\title{
Thermal Performance Evaluation of Large-span Roofs with Ventilating Cavity in Hot Climates: Case Study of Shenzhen Railway Station Hall
}

\author{
Lei Yuan*1 ${ }^{1}$, Lili Shao ${ }^{2}$ and Xuesong $\mathrm{Xu}^{3}$ \\ ${ }^{1}$ Associate Professor, Department of Architecture, Shenzhen University, China \\ ${ }^{2}$ Post Graduate, Department of Architecture, Shenzhen University, China \\ ${ }^{3}$ Architect, Institute of Architectural Design and Research, Shenzhen University, China
}

\begin{abstract}
Roofs of large-span structures always cause severe building energy consumption as well as uncomfortable indoor environments, especially in hot climates. This paper presents the evaluation of a passive roof structure which is designed to significantly reduce roof heat conduction and consequently improve interior comfort. With its ventilating cavity, this roof structure can remove the residual heat between its outer and inner layers. As a case study, the recently built Shenzhen railway station hall and on-site measurement is used for method validation. 3D steady Computational Fluid Dynamics (CFD) simulations, as well as energy consumption simulations, of roof form comparison have been conducted under different conditions. The cross comparison shows that this structure is effective in providing a climatic buffer against hot weather and consequently reduces the enormous energy consumption in large-span structures.
\end{abstract}

Keywords: large-span roof; ventilating cavity; passive cooling; computational fluid dynamics (CFD); energy simulation

\section{Introduction}

Recent years have witnessed the boom of varied kinds of large-span buildings in China, including exhibition halls, gymnasia and railway stations. Due to several common characters, such as high space, large interior volume and numerous occupants, these buildings are extremely energy consuming, especially in hot climate zones.

Among all the factors affecting thermal and energyconsuming performance of large-span buildings, the envelope plays an important role. And of all parts of the building envelope, the roof contributes up to $40 \%$ of HVAC load which accounts for most of the building energy consumption. A roof's energy performance is related to the absorption and transmission of solar radiation. In large-span buildings, the roof exposes much more area to sunlight than other parts of the envelope. And the density of direct solar radiation received by a horizontal roof is much higher than by a vertical façade. Although integrated with insulation to lower its U-Value, the traditional single-layered roof with small mass cannot efficiently prevent solar heat gain of the outer surface from entering the inner space.

*Contact Author: Lei Yuan, Associate Professor,

Department of Architecture, Shenzhen University,

Nanhai Avenue 3688, Shenzhen, China

Tel: +86-755-26534497 Fax: +86-755-26534497

E-mail: yuanlei@szu.edu.cn

(Received April 7, 2014 ; accepted March 4, 2015 )
A double-layer ventilating roof (DLVR) seems to be a promising solution for large-span structures. DLVR is not a new concept. On the contrary, it is one of the most popular passive insulating methods in traditional buildings of southern China and Southeast Asia. Some accurate theoretical calculations and physical experiments have been made on DLVR as well as on a similar envelope structure, i.e. double façade. Sunwoo Lee (2009) measured the heat insulation coefficient of DLVR made of profiled steel. Meng Liu and Wei-ding Long (2011) set up thermal equilibrium equations to predict the thermal performance of an external ventilating double façade in hot-summer and cold-winter regions. With CFD simulation, GaYoung Cho (2013) studied the parameters of double façades to improve ventilating performance in highrise residential buildings. Such researches have proved that ventilation in the cavity between the two layers of a roof or wall can remove solar radiation heat gain by the outer surface and results in energy load reduction.

It will be discussed in this paper whether DLVR in a large-span building, with a tremendous size, can perform effectively. The spatial void space among the huge roof trusses forms a ventilating cavity between the upper surface (commonly roof) and the lower surface (traditionally ceiling). Since the cavity is open to the outdoor atmosphere, the residual heat in it can be taken away by either wind flow or buoyancy. As a result, most of the solar heat gained by the roof is kept away from the indoor space. 
The roof affects energy performance in large-span buildings by changing the vertical gradient of the indoor air temperature. There are many researches focusing on the thermal field in large-span spaces. Yu Li (2002) measured the temperature gradient in the exhibition hall of the Guangdong Modern International Exhibition Center. Lei Zhang (2008) measured the temperature field in the Guangdong Pharmaceutical University Gymnasium which applies natural ventilation technology as a passive energy-saving method. With wind tunnel tests and computer simulations, the roof design for the Sapporo Gymnasium has been optimized to block the prevailing wind in winter and draw in wind in summer and, as a result, reduces energy consumption of the mechanical ventilation and HVAC systems (Shuzo Murakami, 2000). The methods and results of these researches have provided good references for the following case study.

\section{The Study Case}

The waiting hall of Shenzhen railway station is used as a case to analyze the geometries and performances of DLVR. The building is located near the downtown area of Shenzhen, a city in south China. It has a dimension of $300 \mathrm{~m}$ long, $193 \mathrm{~m}$ wide and $17.5 \mathrm{~m}$ high. The ground floor functions as an outdoor platform, while the upper floor as a waiting hall, with two vestibules extending to the south-east and north-west. The roof area of the waiting hall is 3.8 times that of the total glazing façade area and about $50 \%$ of the roof is composed of transparent skylights. Not being disposed of properly, solar heat gain from the roof would result in huge energy waste.

With the energy-saving concern, as well as architectural aesthetic considerations, the roof design is basically a DLVR form: composed of a flat metal surface on the top of trusses and a wave-like surface at the bottom. The elevation differences between the two layers range from $5 \mathrm{~m}$ to $14 \mathrm{~m}$.

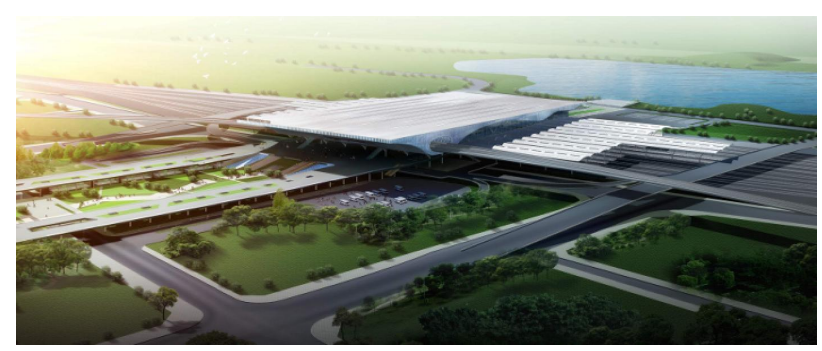

(a) Perspective

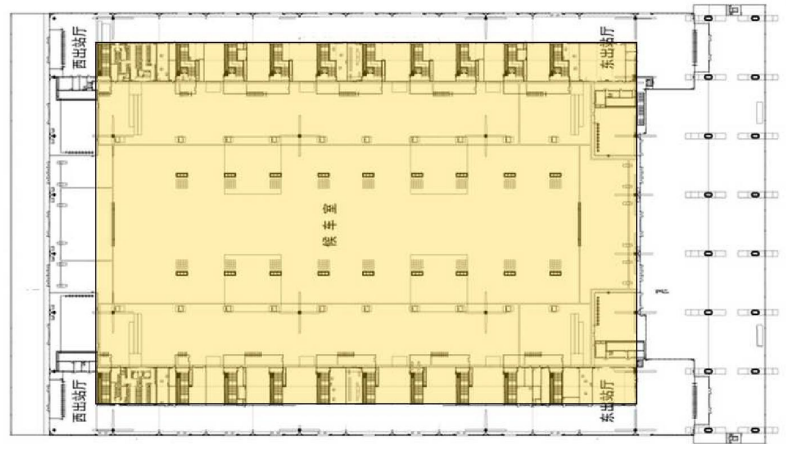

(b) Plan of the Waiting Hall

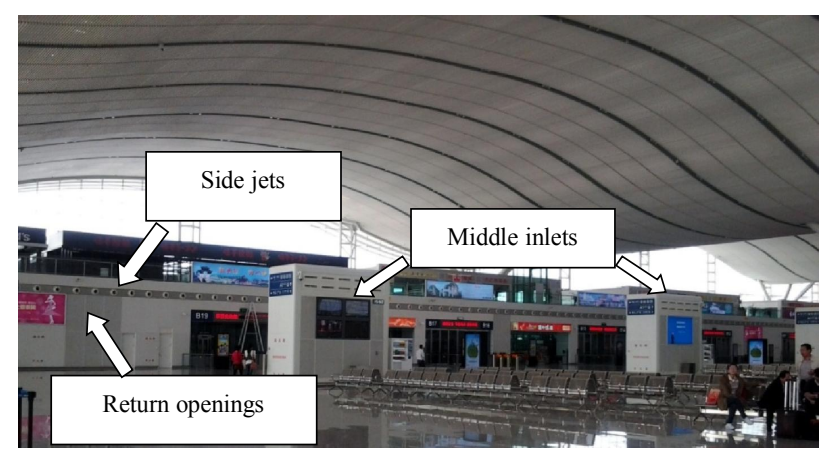

(c) Indoor Space of the Waiting Hall

Fig.1. Shenzhen Railway Station and its Waiting Hall

\section{Thermal Environment Evaluation}

In order to evaluate the thermal performances of different roof designs for large span structures like Shenzhen railway station, on-site measurement, CFD simulations and comparisons are introduced. The objective, as well as the approach of the work at this stage can be reduced to two,

$i$, by comparing and analyzing results obtained by a primary thermal simulation and by on-site measurements, to self-validate the CFD method, including its model conceptualization and parameter settings, in a thermal simulation;

ii, based on the primary self-validation, to conduct CFD simulations of thermal performances of the discussed roof forms in order to rank their effectiveness in preventing roof solar gain and in improving indoor thermal comfort.

\subsection{Primary Thermal Simulations}

\subsubsection{Spatial and Temporal Scope}

Because the research targets the building indoor environment and thermal situation within the roof cavity, the computational domain is set as identical to the space occupied by the building.

By changing the meteorological setups, the thermal situations of different times from 9:00 to 21:00 have been simulated, which yield computational results of temperatures at certain spots that can be compared with on-site measurements. Time variation is set as steady in basic settings. 


\subsubsection{Model Simplification of Geometries and Heat Loads}

Since the building plan is a simple rectangle and its layout is asymmetrical in both the $\mathrm{x}$ and $\mathrm{y}$ dimensions, the building is simplified as a model $1 / 4$ of its original size with two "asymmetrical" sides in order to reduce computational time.

Also the roof is simplified. Its slightly declining roof (with an angle of $1.38^{\circ}$ and elevations from $25 \mathrm{~m}$ to $32 \mathrm{~m}$ ) is modeled as a horizontal roof at a height of $29.5 \mathrm{~m}$. And its wavy ceiling (which is also its shading) hung at heights from $12 \mathrm{~m}$ to $24 \mathrm{~m}$ is modeled as a flat and horizontal ceiling $17.5 \mathrm{~m}$ from the ground. The shading components are modeled as larger ones at larger spans. The retail outlets and small offices in the hall are represented by blocks.

Heat emission by passengers is set as a parameter of the ground with a value of $20 \mathrm{w} / \mathrm{m}^{2}$. Similarly, heat emission by artificial lighting after 17:00 is set to the shading ceiling with a value of $30 \mathrm{w} / \mathrm{m}^{2}$.

\subsubsection{Computational Models}

Meshes:

The mesh type is Hexa Cartesian. The minimum element number is 20 for solid surfaces and $4 \sim 5$ for fluid surfaces such as openings or vents. There are at least 3 hexas under the $1.5 \mathrm{~m}$ level.

To achieve convergence stability in computation demands a reasonable reduction of total mesh hexa amount. The final mesh hexa totals 1,881,452.

Solution settings:

The discretization scheme has been applied. The algorithm adopted in Airpak is one of the pressurevelocity coupling algorithms, namely SIMPLE (SemiImplicit Method for Pressure-Linked Equations). RNG $\mathrm{k}-\varepsilon$ equation is set to turbulence model. Because the purpose of all the thermal simulations discussed in this paper focuses on overall tendency in changes when alternating roof forms, some settings are set to defaults. Standard scheme is used for pressure equation. First- order schemes are set to equations of momentum, temperature, turbulent kinetic energy and turbulent dissipation rate. As a result, analyzing simulations with these settings yields reliable data.

Convergence criterion sets to $10^{-3}$ for energy equation and $10^{-6}$ for other equations. A residual check has been executed, which means that the temperature datum of one certain spot at the level of $1.5 \mathrm{~m}$ has been constantly monitored. Computation is judged as converged after the value no longer fluctuates.

\subsubsection{Material Parameter Settings}

The roofing materials are metal sheets combined with rock wool insulation. The transparent parts on the roof are made of tempered laminated glass with a $\mathrm{U}$-value of $4.85 \mathrm{w} /\left(\mathrm{m}^{2} \cdot \mathrm{K}\right)$.

The clad facades are made of framed glazing ( 6 Low-E+12A+6) with a U-value of $2.685 \mathrm{w} /\left(\mathrm{m}^{2} \cdot \mathrm{K}\right)$ and a shading coefficient (SC) of 0.40 .

\subsubsection{Settings for HVAC System}

All detailed parameters of cooling inlets are set as shown in Table 1.

Table 1. Parameters of Cooling Inlets

\begin{tabular}{|l|l|l|l|l|l|}
\hline \multirow{2}{*}{ Cooling inlet } & \multirow{2}{*}{$\begin{array}{l}\text { Size } \\
(\mathrm{m})\end{array}$} & \multirow{2}{*}{$\begin{array}{l}\text { Height } \\
(\mathrm{m})\end{array}$} & $\mathrm{Inlet}$ & \multicolumn{2}{|l|}{ flow } \\
\cline { 4 - 6 }$\left({ }^{\circ} \mathrm{C}\right)$ & $\begin{array}{l}\mathrm{RH} \\
(\%)\end{array}$ & $\begin{array}{l}\mathrm{V} \\
(\mathrm{m} / \mathrm{s})\end{array}$ \\
\hline Side jets & 0.23 & 5 & 20 & 90 & 10 \\
\hline Middle inlets & $\begin{array}{l}3.2 \times \\
0.16\end{array}$ & $\begin{array}{l}3.8 \\
(4.1)\end{array}$ & 19 & 90 & 6 \\
\hline $\begin{array}{l}\text { Inlets on } \\
\text { ticket booths }\end{array}$ & $\begin{array}{l}1.52 \times \\
0.26\end{array}$ & 2.8 & 19 & 90 & 6 \\
\hline $\begin{array}{l}\text { Inlets at } \\
\text { entrances }\end{array}$ & $\begin{array}{l}1.52 \times \\
0.26\end{array}$ & 2.8 & 16 & 90 & 10 \\
\hline
\end{tabular}

\subsection{On-site Measurement}

Surface temperatures at different heights, which are $1.5 \mathrm{~m}, 3 \mathrm{~m}, 5 \mathrm{~m}, 8 \mathrm{~m}$ and $11 \mathrm{~m}$, of two columns within the modeled area are measured on site. The results can be seen as the same with air temperatures near the measured point on the condition that the columns have

Table 2. Comparison of Measured Temperature Values $\left(\mathrm{T}_{\mathrm{m}}\right)$ and Computational Temperature Values

\begin{tabular}{|c|c|c|c|c|c|c|c|c|c|c|}
\hline \multirow{2}{*}{ Time } & \multicolumn{2}{|c|}{$\mathrm{H}=1.5 \mathrm{~m}$} & \multicolumn{2}{|l|}{$\mathrm{H}=3 \mathrm{~m}$} & \multicolumn{2}{|l|}{$\mathrm{H}=5 \mathrm{~m}$} & \multicolumn{2}{|l|}{$\mathrm{H}=8 \mathrm{~m}$} & \multicolumn{2}{|c|}{$\mathrm{H}=11 \mathrm{~m}$} \\
\hline & $\mathrm{T}_{\mathrm{m}}$ & $\mathrm{T}_{\mathrm{c}}$ & $\mathrm{T}_{\mathrm{m}}$ & $\mathrm{T}_{\mathrm{c}}$ & $\mathrm{T}_{\mathrm{m}}$ & $\mathrm{T}_{\mathrm{c}}$ & $\mathrm{T}_{\mathrm{m}}$ & $\mathrm{T}_{\mathrm{c}}$ & $\mathrm{T}_{\mathrm{m}}$ & $\mathrm{T}_{\mathrm{c}}$ \\
\hline 9:00 & 29.3 & 27.72 & 29.8 & 27.58 & 29.9 & 27.8 & 30.2 & 27.93 & 30.7 & 27.91 \\
\hline 10:00 & $\underline{29.8}$ & 29.47 & $\underline{30.3}$ & $\underline{29.4}$ & $\underline{30.5}$ & $\underline{29.57}$ & $\underline{30.9}$ & $\underline{29.37}$ & $\underline{30.9}$ & $\underline{29.57}$ \\
\hline 11:00 & $\underline{30.7}$ & $\underline{31.11}$ & $\underline{31.1}$ & $\underline{30.86}$ & $\underline{30.9}$ & $\underline{30.66}$ & $\underline{31.4}$ & $\underline{30.53}$ & $\underline{31.7}$ & $\underline{30.49}$ \\
\hline $12: 00$ & $\underline{30.6}$ & $\underline{30.32}$ & $\underline{30.8}$ & $\underline{30.1}$ & $\underline{31.1}$ & $\underline{30.08}$ & $\underline{31.7}$ & $\underline{30.64}$ & $\underline{31.9}$ & $\underline{31.64}$ \\
\hline 13:00 & $\underline{30.8}$ & $\underline{31.46}$ & $\underline{31.1}$ & $\underline{31.16}$ & $\underline{31.2}$ & $\underline{30.91}$ & $\underline{31.4}$ & $\underline{30.78}$ & $\underline{31.7}$ & $\underline{30.99}$ \\
\hline 14:00 & $\underline{30.8}$ & $\underline{31.64}$ & $\underline{31.2}$ & $\underline{31.57}$ & $\underline{31.5}$ & $\underline{31.7}$ & $\underline{31.7}$ & $\underline{31.74}$ & $\underline{31.8}$ & $\underline{31.72}$ \\
\hline $15: 00$ & 30.9 & 32.69 & 31.4 & 32.59 & 31.7 & 32.79 & 31.9 & 32.93 & 32.4 & 32.6 \\
\hline 16:00 & 31.1 & 30.72 & 31.6 & 30.94 & 31.8 & 31.7 & 31.9 & 32.06 & 32.5 & 32.26 \\
\hline 17:00 & 31.3 & 28.81 & 31.7 & 28.92 & 31.9 & 29 & 32.1 & 29.53 & 32.9 & 29.9 \\
\hline 18:00 & 31.2 & 27.15 & 31.4 & 27.06 & 31.7 & 26.94 & 32.1 & 26.85 & 33.3 & 26.63 \\
\hline 19:00 & 31.1 & 23.97 & 31.2 & 24.04 & 31.6 & 24.41 & 31.9 & 24.97 & 32.6 & 25.33 \\
\hline 20:00 & 30.6 & 23.04 & 31.1 & 23.09 & 31.3 & 23.25 & 31.7 & 23.71 & 32.6 & 24.3 \\
\hline 21:00 & 30.8 & 22.88 & 31.2 & 22.86 & 31.4 & 23.03 & 32.1 & 23.72 & 32.8 & 23.87 \\
\hline
\end{tabular}


not received direct solar radiation. The positions where on-site measurements have been carried out are shown in Fig. 2 .

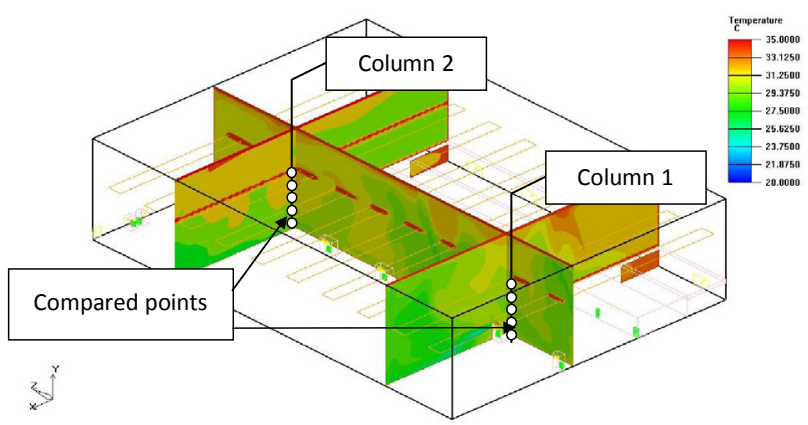

Fig.2. Modeled Area and Position for Temperature Result Comparison

\subsection{Analyzation and Validation of Primary Thermal Simulation}

Results of temperature values obtained by on-site measurements and by computational simulations are listed in Table 2. And data obtained at the levels of $1.5 \mathrm{~m}$ and $5 \mathrm{~m}$ are used to show differences between simulations and real situations (See Fig.3.).

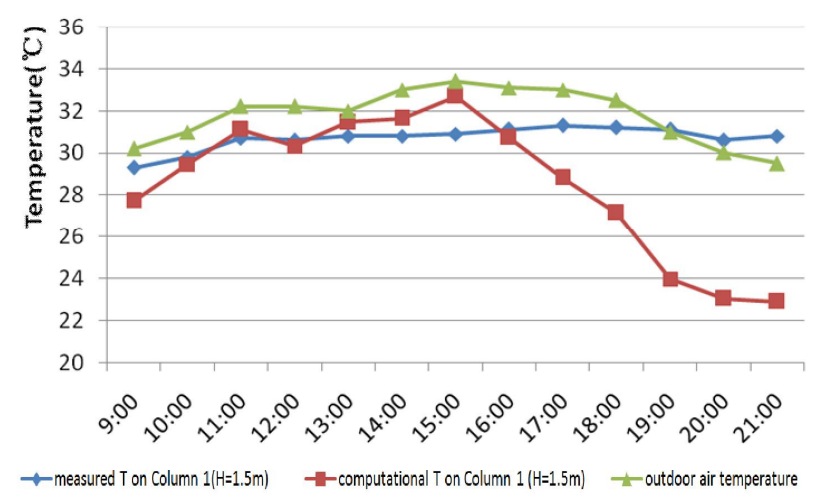

(a) Measured and Computational Temperature Values at the $1.5 \mathrm{~m}$ Level on Column 1

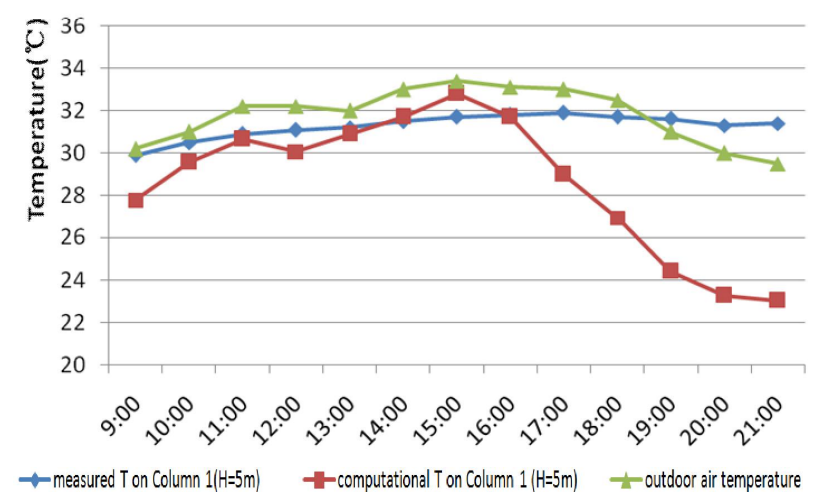

(b) Measured and Computational Temperature Values at the $5 \mathrm{~m}$ Level on Column 1

Fig.3. Temperature Results at the Position of Column 1

In data comparison between different sources, the changing tendency of simulated temperature data is in general accordance with that of measured results. And differences between the temperature results from different sources are relatively minor and no more than $0.5^{\circ} \mathrm{C}$, if only data from 9:00 to $12: 00$ are referred to.

From 13:00 on, differences increase and the simulated temperature values drop more quickly than the measured ones. On-site observation can reason the divergence in that, in the afternoon, manual adjustment of the HVAC system has been executed by the station staffs who are concerned about energy cost by using A/C. Without such manual adjustment, results by simulation may be even more compatible with measured data.

It can be reasonably concluded that the primary thermal simulation by CFD software Airpak, as well as its settings, can yield reliable results to meet the objectives of the subsequent thermal simulations.

\subsection{Thermal Performance Simulations of Different Roof Forms \\ 3.4.1 Simulation Settings}

The computational domain is the same with that in primary thermal simulation. And two materials are used for the outer roof layers in Scheme $\mathrm{C}$ and D, i.e. composite panels made of aluminum and rock wool and tempered laminated glazing. The thermal characters of the envelope materials are the same as those in the primary simulation.

Because solar irradiance reaches its peak at 12 o'clock and also because the primary simulation has yielded best results under the conditions of 10, 11 and 12 o'clock, the simulation time in this part is sent to 12:00 on July 11 th.

Computational settings such as discretization scheme, meshes and converge standard in the primary simulation are also used in simulating the thermal performances of the discussed roof types.

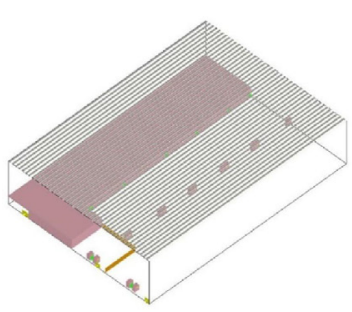

Scheme A

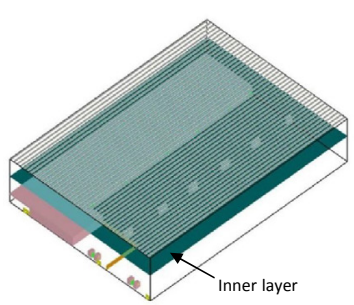

Scheme C

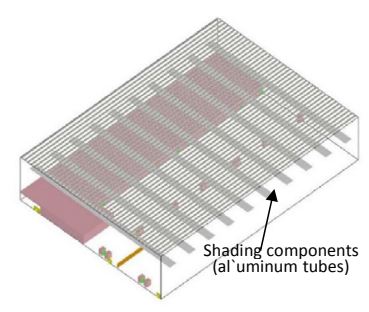

Scheme B

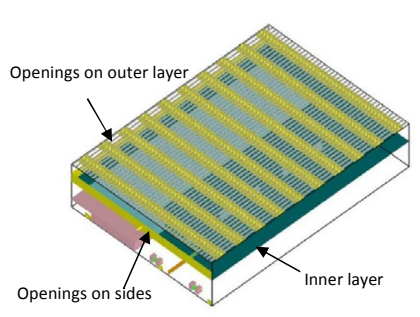

Scheme D
Fig.4. Models with Different Roof Schemes 
Table 3. Properties of the Roof Forms

\begin{tabular}{|l|c|l|}
\hline Scheme & $\begin{array}{l}\text { Indoor } \\
\text { space } \\
\text { height }(\mathrm{m})\end{array}$ & Characteristics \\
\hline $\begin{array}{l}\text { Scheme A } \\
\text { (Single layer roof } \\
\text { w/o shading) }\end{array}$ & 29.5 & - \\
\hline $\begin{array}{l}\text { Scheme B } \\
\text { (Single layer roof } \\
\text { with shading) }\end{array}$ & 29.5 & $\begin{array}{l}\text { Indoor shadings: } \\
\text { Horizontal curtain of aluminum } \\
\text { tubes, at the height of } 17.5 \mathrm{~m}, \\
\text { SC=0.33 }\end{array}$ \\
\hline $\begin{array}{l}\text { Scheme C } \\
\text { (Double layer } \\
\text { roof with closed } \\
\text { cavity) }\end{array}$ & 17.5 & $\begin{array}{l}\text { Material of inner layer of roof } \\
\text { structure: } \\
\text { Transparent polycarbonate } \\
\left.\text { sheets, U=4.44 W/(m }{ }^{2} \cdot \mathrm{K}\right), \\
\text { SC=0.20. }\end{array}$ \\
\hline $\begin{array}{l}\text { Scheme D } \\
\text { (Double layer } \\
\text { ventilating roof, } \\
\text { DLVR) }\end{array}$ & 17.5 & $\begin{array}{l}\text { Material of inner layer of roof } \\
\text { structure: } \\
\text { Transparent polycarbonate } \\
\left.\text { sheet, U=4.44 W/(m }{ }^{2} \cdot \mathrm{K}\right), \\
\text { SC=0.20. } \\
\text { Openings on roof sides: } \\
\text { Openings of } 6 \mathrm{~m} \text { high run all } \\
\text { along the roof sides. Opening } \\
\text { ratio is } 50 \% . \\
\text { Opening on outer layer: } \\
\text { Opening ratio is } 25 \% \text { Pressure } \\
\text { condition is steady pressure. }\end{array}$ \\
\hline
\end{tabular}

\subsubsection{Results and Findings}

Thermal performances of the four schemes are compared and ranked using temperature and wind velocity data. And some findings are listed as below,

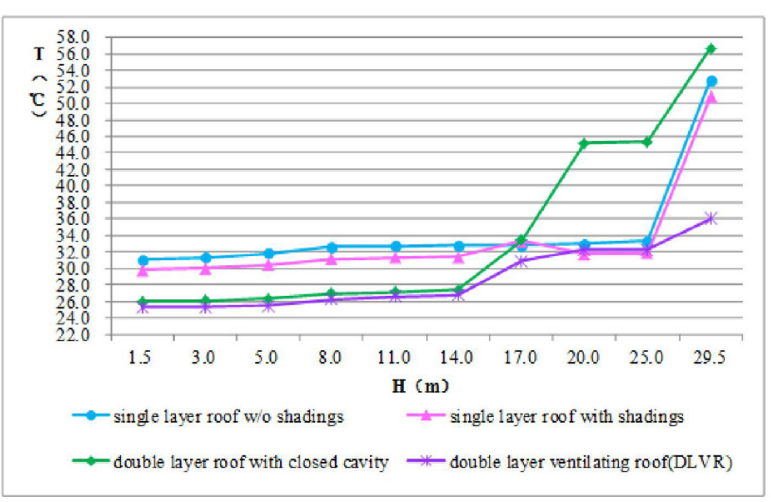

Fig.5. Computational Temperature Values of the Four Roofs at Different Levels

1) An overall temperature-declining trend.

Average temperatures on 10 different levels in the four simulations can be seen in Fig.5., which shows obvious declination in temperature from Scheme A to D simulation. DLVR yields the lowest temperatures of all levels except the $20.0 \mathrm{~m}$ and $25.0 \mathrm{~m}$ level. On these two heights, heated air in the roof cavity gathers because of buoyancy and ventilation is not sufficient to take it away.

Temperature contours of representative sections used for comparison are shown below (see Fig.6.a b).

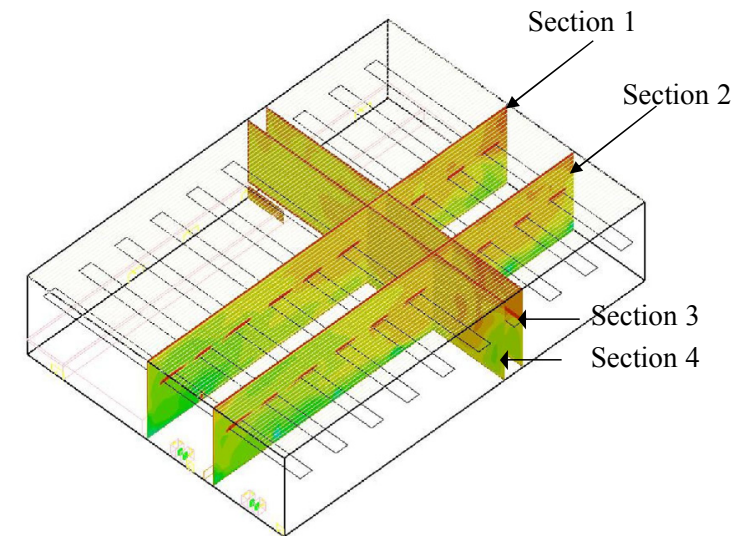

(a) Positions of the Sections Used to Show Temperature Contours
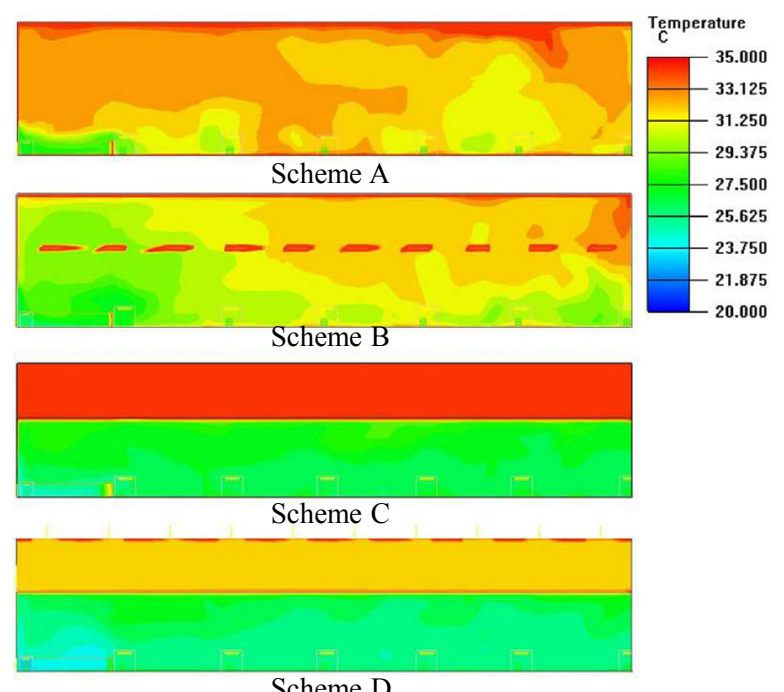

(b) Temperature Contours in Section 1

Fig.6. Temperature Contours of Different Roof Schemes

In the simulation of Scheme A, under the single layer roof (w/o shading), the indoor air has the highest average temperature and a visible temperature gradient in y dimension. By scheme B, shading components hung under the roof have blocked out part of the solar radiation and cause a temperature decrease on one hand. While on the other they also absorb solar radiation, become heated and release heat to indoor air. On the whole, shadings under the roof are not capable of mitigating indoor thermal discomfort significantly.

Whereas, the two double layer roofs show great potential in effectively cooling indoor air and enhancing evenness of the indoor temperature field.

2) Thermal situations in $\mathrm{A} / \mathrm{C}$ controlling zone.

The simulated results of average temperature in the $\mathrm{A} / \mathrm{C}$ controlling zone, i.e. the indoor space below $5 \mathrm{~m}$ high, in different roof conditions are, $32.9^{\circ} \mathrm{C}$ for single layer roof w/o shading, $31.5^{\circ} \mathrm{C}$ for single layer roof with shading, $28.0^{\circ} \mathrm{C}$ for double layer roof with closed cavity and $27.5^{\circ} \mathrm{C}$ for DLVR. The thermal environment has been significantly improved in respect of absolute temperature value and temperature evenness. 
Compared with the simple single layer roof structure, DLVR has reduced the temperature at the pedestrian level $(\mathrm{H}=1.5 \mathrm{~m})$ by $5.7^{\circ} \mathrm{C}$ and also reduced the average temperature in the $\mathrm{A} / \mathrm{C}$ controlling zone by $5.4^{\circ} \mathrm{C}$.

3) Thermal situations within the buffer zone (cavity).

Both of the double layer roofs have induced high temperatures in the buffer zone, i.e. the space within the cavity. The air in the closed roof cavity is heated by solar radiation to an average temperature of $44.97^{\circ} \mathrm{C}$. And when there is no convection with the air outside the cavity, heat can only be conducted out through the top, bottom and sides of the cavity extremely slowly. By contrast, within the cavity of DLVR, ventilation driven by both inlet wind pressure and buoyancy plays an important role in eliminating heat residue. When ventilation works efficiently, the air flow in the cavity is like the situation seen in the wind velocity illustration in Section 3 (See Fig.7.a). The inlet flow comes in from the side openings, goes straightforward through the cavity, and passes through openings on the roof outer layer, especially openings near the center, taking the heated air away, which results in a relatively low average temperature $\left(32.8^{\circ} \mathrm{C}\right)$ in the cavity and much less heat conduction into the indoor space.

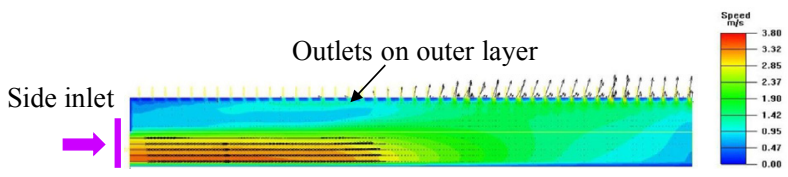

(a) Doubled Contour and Vector Illustration of Wind Speed in Roof Cavity in Section 3

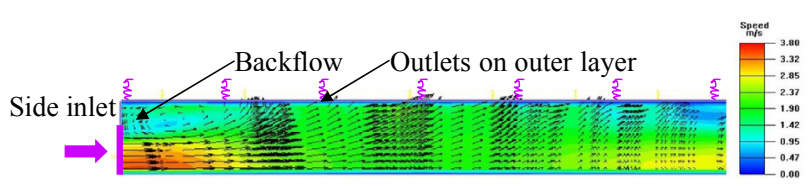

(b) Doubled Contour and Vector Illustration of Wind Speed in Roof Cavity in Section 1

Fig.7. Doubled Contour and Vector Illustrations of Wind Speed in Roof Cavity
Whereas, the ventilation is not always so straightforward and efficient. When a DLVR has too large a length or width, the inner surface frictions might override wind or buoyancy and dominate the fluid process. As is the case shown in Fig.7.b, when this happens, wind in the buffer zone slows down especially in the center of the roof structure and backflow occurs.

\subsubsection{Brief Summary}

If we use the results of single layer roof simulation as the control group, it can be concluded that,

$i$, a single layer roof with shading has its limit in improving indoor thermal environment;

ii, DLVR is the best form among these four roof forms and has proved its effectiveness in reducing indoor air temperature and improving indoor temperature evenness.

Furthermore, when comparing the thermal performances of the two double layer structures, we should take into account that, Airpak does not involve heat accumulation before the simulated moment in temperature computation. This implies that DLVR might have even more advantages over a double layer roof with closed cavity than what has been shown above.

\section{Energy Efficiency Simulation}

The experimental method of orthogonal design is introduced in the optimization research of DLVR as a climatic buffer. The resulting parameters have been used in the following energy consumption research.

The software of DesignBuilder is used as the simulating tool in this procedure.

\subsection{Simulation Settings}

Common settings:

Computational domain: $\mathrm{L} 150 \mathrm{~m} \times \mathrm{W} 150 \mathrm{~m} \times \mathrm{H} 25.5 \mathrm{~m}$,

External wall: Low-E glazing,

Inner layer of roof: Transparent polycarbonate sheets $17.5 \mathrm{~m}$ above the ground.

Climatic settings: With the long hot humid summer of about six months and short wintertime, Shenzhen usually receives abundant solar radiation. According

Table 4. The Differences between Double Layer Roof with Closed Cavity and Double Layer Ventilating Roof

\begin{tabular}{|l|l|}
\hline Double layer roof with closed cavity & Double layer ventilating roof (DLVR) \\
\hline
\end{tabular}


to the standard meteorological yearly data of the city, solar radiation amounts to $4617.9 \mathrm{MJm}^{2}$. And July has the most sunlight hours and solar radiation. Average wind speed is $2.6 \mathrm{~m} / \mathrm{s}$ and the prevailing wind direction is SE.

Energy load settings: According to Appendix B of the national standard GB50189-2005, HVAC using time is from 8:00 to $21: 00$, cooling temperature is set to $25^{\circ} \mathrm{C}$, heating temperature set to $18^{\circ} \mathrm{C}$, electrical lighting load is $12 \mathrm{~W} / \mathrm{m}^{2}$, lighting time: auto-adjusted according to daylight luminance situation, occupancy load is $3 \mathrm{~m}^{2} /$ per computer and equipment load is $13 \mathrm{~W} / \mathrm{m}^{2}$.

By adopting a cavity model and inside convection algorithm, natural convection within the roof cavity can be computed. The envelope air tightness defaults as an air infiltrating velocity of $0.7 \mathrm{ac} / \mathrm{h}$.

\subsection{Computational Results of Energy Consumption}

1) Hourly results of cooling load in summer.

Building cooling load is composed of indoor heat gain and envelope heat gain. Indoor heat gain can be subdivided into different heat gains such as solar, lighting, equipment and occupancy heat gain, while heat gains by roof, external wall, glazing and ground as well as envelope infiltration belong to envelope heat gain.

The 15 th of July is defaulted as the modeled condition in summer cooling load simulation in DesignBuilder 3.0. The computational results are shown in Fig.8.

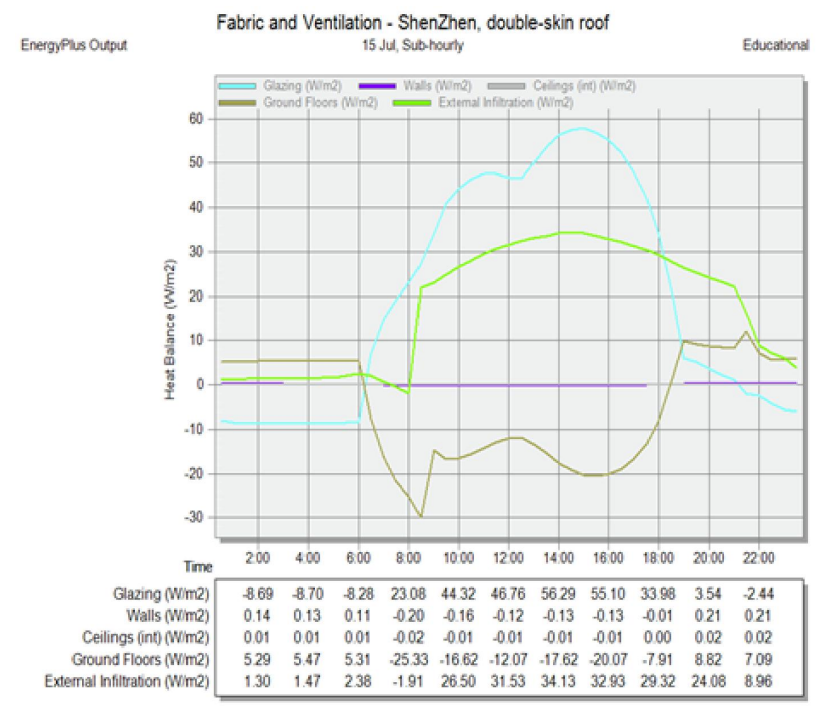

(a) Double Layer Roof with Closed Cavity

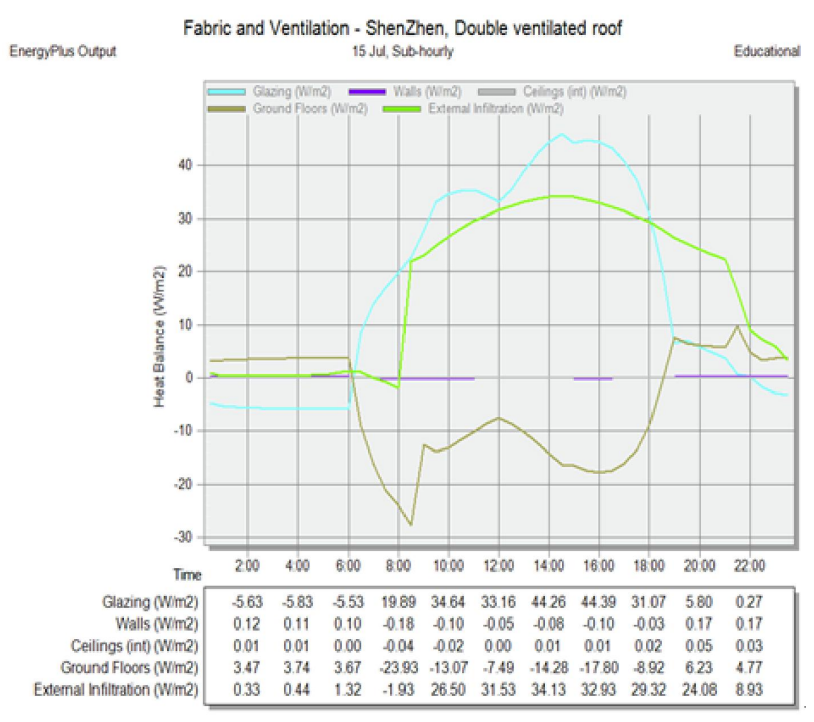

(b) Double Layer Ventilating Roof (DLVR)

Fig.8. Hourly Summer Cooling Load by Envelope

The two different roof form conditions yield similar results in that,

i, glazing and external infiltration comprises the largest fraction among all loads,

ii, cooling load value peaks at about 15:00 for the closed cavity roof and at 14:30 for the ventilating roof. After 19:00, it falls rapidly. During the night heat accumulated in the closed cavity cannot be removed effectively, which causes a relatively large cooling demand in the morning.

Although the difference in total cooling load of the two roofs is not significant, DLVR does yield a better result in this part.

2) Yearly energy load.

Computational results of yearly energy load for both roof forms are shown in Table 5. and Fig.9.

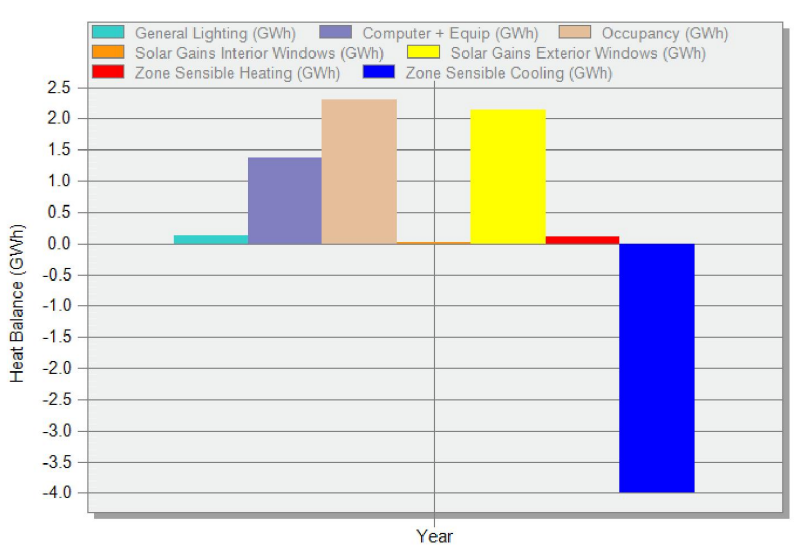

(a) Double Layer Roof with Closed Cavity 


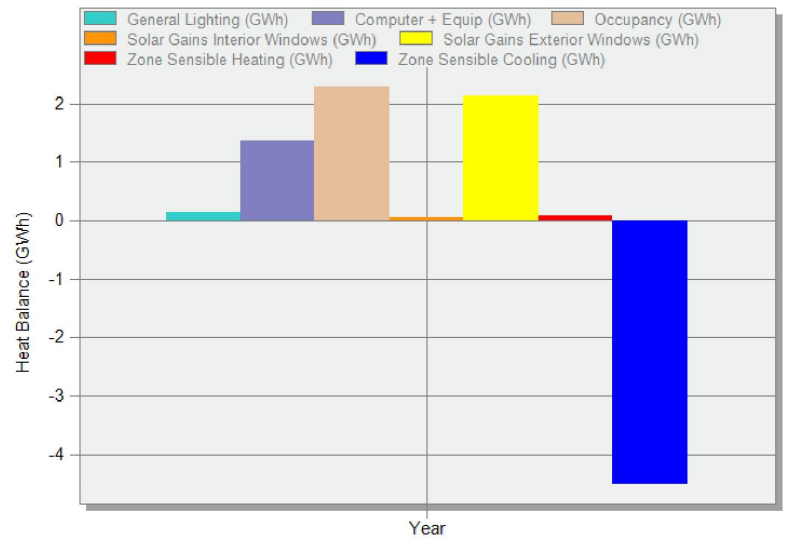

(b) DLVR

Fig.9. Hourly Unit Area Cooling Load of the Envelope in Summer Designed Day

Table 5. Yearly Results of Energy Load (GWh)

\begin{tabular}{lcc}
\hline Energy loads & $\begin{array}{c}\text { Double layer roof w. } \\
\text { closed cavity }\end{array}$ & DLVR \\
\hline General Lighting & 0.13 & 0.13 \\
Computer + Equipment & 1.38 & 1.38 \\
Occupancy & 2.29 & 2.3 \\
Solar Gains Interior & 0.07 & 0.01 \\
Windows & & \\
Solar Gains Exterior & 2.14 & 2.14 \\
Windows & 0.09 & 0.11 \\
Zone Sensible Heating & -4.5 & -3.99 \\
\hline
\end{tabular}

Despite its advantage in insulating, the closed cavity structure shows significant disadvantage in inner layer heat gain which is 7 times that of the value for DLVR. This results in its $12.8 \%$ extra energy demand in yearly total energy consumption compared with DLVR.

\subsection{Findings in Energy Consumption Simulations}

Energy simulation results are coincident with thermal simulation results in that, by eliminating heated air within the roof structure and thus reducing indoor heat gain through the inner layer of the roof, DLVR cools the inner air down in the large span hall in an effective way. Subsequently cooling demand decreases significantly, which mitigates the enormous energy-consumption of large span buildings.

\section{Conclusion}

Using the study case of the Shenzhen railway station waiting hall, the concept of DLVR in largespan buildings has been tested by simulations of environment thermal comfort and energy load. According to simulation results and comparisons, DLVR is proved to be an effective passive cooling technology for large-span buildings in hot climates in respect of indoor comfort improvement as well as energy saving.

\section{Acknowledgments}

The authors are grateful for the financial support provided by a grant from the National Natural Science Foundation of China (Project No. 51278308). The authors would also like to thank SUIADR and the designers of the Shenzhen railway station hall for their support concerning our investigation.

\section{References}

1) Li, C. (2010) Building ventilation strategy in large space. 1st ed. Beijing: China building industry press.

2) Chang, P. and Chang, C. (2008) Development and preliminary evaluation of double roof prototypes incorporating RBS (radiant barrier system), Energy and Buildings, 40(2), pp.140-147.

3) Ga-Young Cho, Myoung-Souk Yeo and Kwang-Woo Kim (2013)Design parameters of double-skin façade for improving the performance of natural ventilation in high-rise residential buildings, Journal of Asian Architecture and Building Engineering, 12(1), pp.125-132.

4) Azevedo, L. And Sparrow E. (1985) Natural convection in openended inclined channel, Journal of Heat Transfer, 106, pp.893-901.

5) Biwole, M. and Wolosz, y. n. (2008) Heat transfers in a double skin roof ventilated by natural convection in summer time, Energy and Building, 40(8), pp.487-1497.

6) Lee, S., Park, S. And Yeo, M. (2009) An experimental study on airflow in the cavity of a ventilate roof, Building and Environment, 44(7): 1431-1439.

7) Yuan, L. Shao, L. and Xu, X. (2012) Optimizing research on the clad facade of a high-rise building using CFD Method. Frontiers of Green Building, Mechanics and Civil Engineering II, pp.193194, pp.1284-1289.

8) University of Illinois and Lawrence Berkeley National Laboratory (2009) Engineering Reference: The Reference to EnergyPlus Calculation.

9) EnergyPlus Documentation Main Menu-Input/Output Reference: 263-287.

10) EnergyPlus Simulation Documentation for DesignBuilder v3.0: 280-281. 